\title{
CISTO DE COLÉDOCO COMO ACHADO INCIDENTAL ULTRASSONOGRÁFICO: RELATO DE CASO E REVISÃO DA UTTERATURA
}

\author{
An incidental choledochal cyst found on ultrasonography: a case report and review of literature
}

Solon Cavalcanti GUERRA, Uirá Fernandes TEIXEIRA

Trabalho realizado no Hospital Santo Antônio, Associação Obras Sociais Irmã Dulce, Salvador, BA, Brasil.

\section{Correspondência:}

Uirá Fernandes Teixeira, e-mail: uiraft@yahoo.com.br

Fonte de financiamento: não há

Conflito de interesses: não há

Recebido para publicação:

Aceito para publicação:

\section{INTRODUÇÃO}

$\longrightarrow$ cisto de colédoco é doença rara dos ductos biliares que consiste na presença de uma ou mais dilatações que podem acometer qualquer local da árvore biliar. Trata-se de doença que é diagnosticada, na maior parte dos casos, nos primeiros anos de vida, em crianças e recém-nascidos que se apresentam com sintomas da síndrome de icterícia obstrutiva ${ }^{2}$. Entretanto, cerca de $20-30 \%$ dos casos manifestam-se na idade adulta, com sinais e sintomas muitas vezes inespecíficos ${ }^{9}$.

Existem algumas teorias para explicar o surgimento da doença. A mais aceita é que exista junção anômala entre a via biliar comum e o ducto pancreático principal, fazendo com que as enzimas pancreáticas atinjam o colédoco e provoquem danos à sua parede. Alguns estudos relataram a presença dessa junção anormal em cerca de $90 \%$ de pacientes portadores de cistos de colédoco ${ }^{7}$.

A importância do diagnóstico dessa doença decorre da necessidade de se fazer o tratamento adequado em virtude da possibilidade de surgimento de graves complicações, dentreasquaisestão a colangite, pancreatite, a ruptura do cisto e a possibilidade de degeneração maligna com surgimento de colangiocarcinoma ${ }^{6}$. O tratamento de eleição é cirúrgico, com a completa excisão do cisto e restauração da drenagem da bile através de uma derivação bileodigestiva, quando possível.

\section{RELATO DO CASO}

Mulher de 42 anos compareceu ao ambulatório de cirurgia geral do Hospital Santo Antônio / Obras Sociais Irmã Dulce, trazendo exame ultrassonográfico de abdome total. Ela não apresentava queixa alguma; negava dor abdominal, perda de peso, icterícia ou outros sintomas colestáticos. Ao exame físico não apresentava nenhuma alteração; encontrava-se em bom estado geral, anictérica, afebril, com abdome flácido e indolor, sem massas palpáveis. Em sua história pregressa referia passado de neoplasia de colo uterino tratada por quimio e radioterapia há 10 anos, sendo acompanhada desde então. Ao ser solicitada nova ultrassografia para seguimento que foi descoberto o cisto de colédoco, medindo 4,4 x 3,7 x 3,4 cm sem outros achados neste exame inicial. Foram solicitados exames laboratoriais marcadores de colestase (que foram normais) e uma colangiopancreatografia endoscópica retrógrada (CPER) que mostrou uma formação cística em hepatocolédoco de $4 \times 5 \mathrm{~cm}$, com colédoco distal medindo $0,4 \mathrm{~cm}$, vesícula biliar opacificada e vias biliares sem outras alterações (Figura 1).

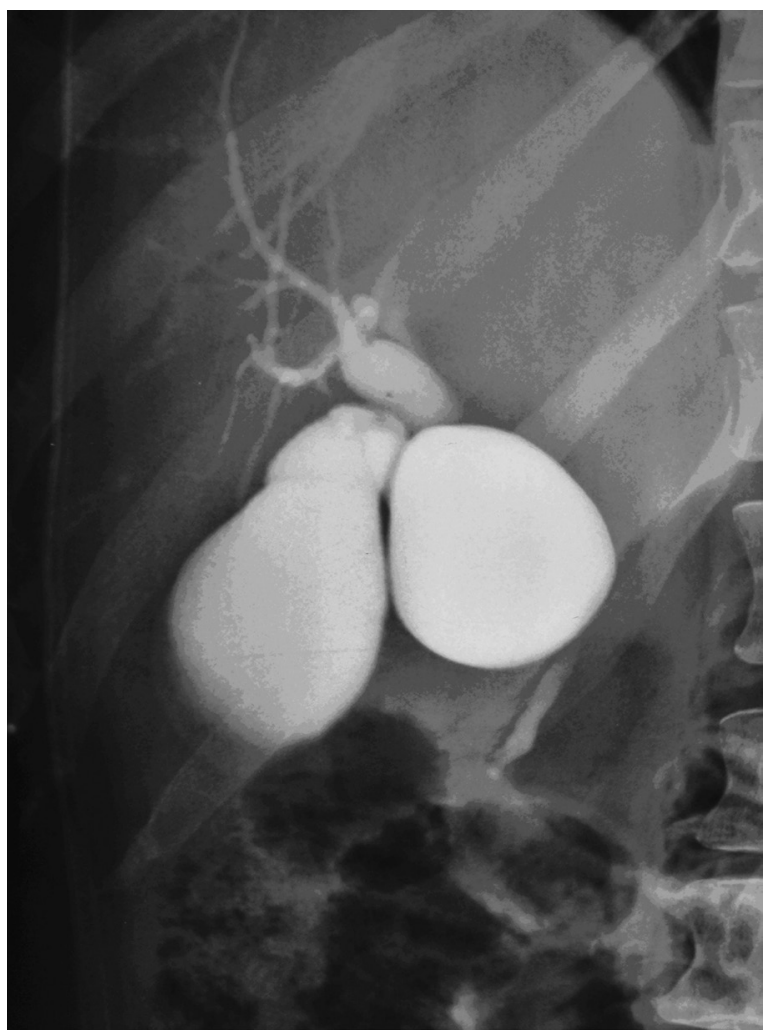

FIGURA 1 - CPER evidenciando o cisto de colédoco e sua relação com a vesícula biliar 
Foi então discutido o caso com a paciente e decidido em conjunto pelo tratamento cirúrgico. No intra-operatório, após a abertura da cavidade peritoneal, visualizava-se uma formação cística que acometia a via biliar extra-hepática, medindo cerca de $5 \mathrm{~cm}$ de diâmetro. A vesícula biliar encontrava-se em sua posição habitual, mas o ducto cístico drenava para o cisto (cisto de tipo Ia de Todani). Foi feito o isolamento cuidadoso do hepatocolédoco desde a junção dos hepáticos até a porção supra-pancreática. O cisto foi então ressecado e retirado juntamente com a vesícula, com sepultamento do colédoco distal e reconstrução da drenagem biliar através de uma hepaticojejunostomia em Y-de-Roux. Um dreno sentinela foi posicionado próximo à anastomose. A operação transcorreu sem intercorrências.

No primeiro dia de pós-operatório encontrava-se anictérica, afebril, com pouca dor ao redor da ferida operatória. O dreno sentinela havia produzido $100 \mathrm{ml}$ de secreção serohemática. A ferida operatória encontravase limpa e seca. A dieta líquida foi introduzida e evoluída conforme aceitação desde então, sem complicações. Ela evoluiu bem no pós-operatório, com fístula biliar de baixo débito drenada e com marcadores de colestase normais; teve o dreno retirado no $11^{\circ}$ dia e recebeu alta hospitalar três dias depois. O laudo da anatomia patológica não mostrou degeneração maligna.

\section{DISCUSSÃO}

O acesso crescente da população aos exames de imagem vem permitindo o diagnóstico de doenças raras, muitas vezes de forma incidental. É o caso da paciente em questão que, após uma ultrassonografia de abdome total, teve detectado um cisto de colédoco, mesmo encontrando-se assintomática aos 42 anos de idade, fato incomum na história natural desta doença5.

Alonso-Lej et al., modificado por Todani el al., elaboraram a classificação mais utilizada atualmente para os cistos de colédoco, dividindo-os em cinco tipos $^{8}$. O tipo I é o mais comum, representando cerca de $80 \%$ dos casos segundo relatos ${ }^{7}$. A apresentação clínica é mais exuberante nas crianças e recém-nascidos. Em adultos os sintomas são variáveis, com um espectro variando desde dor abdominal inespecífica até casos graves de colangite ou pancreatite aguda.

O surgimento de colangiocarcinoma é complicação sombria dos cistos de colédoco, presente em até 19\% dos casos à época do diagnóstico, muito maior do que a incidência na população geral ${ }^{1}$. Tal fato faz da ressecção cirúrgica completa o melhor tratamento para estes pacientes, factível em muitos casos de cistos tipo I e II ${ }^{1}$.

A aceitação, por parte de paciente assintomático, em submeter-se a operação que pode apresentar grandes complicações como hepaticojejunostomia em Y-de-Roux, pode representar desafio para o cirurgião. Acredita-se que boa relação médico-paciente faz-se necessária, com a exposição adequada da história desta doença e suas potenciais complicações por parte do médico, tornando esse processo mais fácil e garantindo o melhor tratamento para o paciente.

\section{REFERÊNCIAS}

1. Atkinson $H$, De Jong $C$, Fischer $C$, Madhavan $K$, Parks $R$ et. al. Choledochal cysts in adults and their complications. HPB. 2003; 5(2): 105-110.

2. Bittencourt DG, Bustorff-Silva JM, Hessel G, Pereira LH, Sbragia L. Cisto de colédoco: experiência de 10 anos. J. Pediatr. 2000; 76(2): 143-148.

3. Coelho G, Falcone C, Rodrigus MA, Sousa AV, Veiga DK et. al. Tratamento endoscópico de cisto de colédoco do tipo III. Arq Bras Cir Dig. 2008; 21(3): 139-141.

4. Fan ST, Liu CL, Lo CM et al. Choledochal cysts in adults. Arch Surg. 2002; 137: 465-468.

5. Goss JA Jr, Jordan PH Jr, Rosenberg WR, Woods KL. Some considerations for management of choledochal cysts. Am J Surg. 2004; 187(6):790-795.

6. Jesus LE, Judice MM, Mello EG, Nogueira PAV. Cisto de colédoco: experiência de cinco anos com o tratamento cirúrgico no hospital municipal Jesus-RJ. Rev Col Brás Cir. 2002; 29(6): 336-341.

7. Miyano T, Yamataka A. Choledochal cysts. Curr Opin Pediatr. 1997; 9(3): 283-288.

8. Narusue $M$, Todani T, Watanabe $Y$ et al. Congenital bile duct cysts: classification, operative procedures, and review of thirty-seven cases including cancer arising from choledochal cyst. Am J Surg. 1977; 134: 263-269.

9. Pereira AD, Rosa I, Santos AA et al. Quisto do colédoco como causa de obstrução biliar no adulto. J Port Gastrenterol. 2007; 14(4): 204207. 